\title{
Design and Implementation of Naval Combat System using Virtualization Technology
}

\author{
[Joong-Hyuck Cha, Ha-Yeon Lee, and Dong-Seong Kim*]
}

\begin{abstract}
This paper proposes a virtualization environment for a naval combat system. Generally, the naval combat system is composed of numinous input/output sensors, high-performance engines and devices for electronic warfare, guidance/reconnaissance. The previous technique, which is used distributed naval combat system, has a weakness that has a lack of end-to-end delay time, packet delay time, and utilization. To solve these problems, this paper proposes virtualization environment on naval combat system. Simulation results show that an availability of increased performance in naval system in terms of end-to-end delay time, packet delay time, and utilization.
\end{abstract}

Keywords - Naval Combat System, Virtual Machine, Virtualization Technology, Performance Evaluation.

\section{Introduction}

The naval combat system requires a system that integrates functions for electronic warfare and relay in simultaneous battle situation, based on ability to respond in real time various enemy attack threats through accurate detection. A number of sensor nodes in a naval combat system, equipped based on distributed networks control, update and exchange in real time large amounts of data with each information processing device[1-3]. According to it, network traffic is caused and makes occurs problems to the nodes in naval combat system, such as noise, heat problems in the battle information room as well as CPU overload[4][5]

Meanwhile, as a change of the recent traffic pattern and the necessity of R\&D on the development of a new network architecture have been raised, studies on techniques applicable to a network have been actively carried out[6]. Network virtualization technology means a technology that logically integrates different systems physically, or vice versa, logically partition one system using it efficiently[7].

In this paper, we propose a network virtualization technique to solve network traffic problem in naval combat system. In addition, this paper applies it to the system and verifies the suitability of virtualization system using a multifunctional console. The proposed technique is constructed

Joong-Hyuck Cha

Kumoh National Institute of Technology

Republic of Korea

Ha-Yeon Lee

Kumoh National Institute of Technology

Republic of Korea

Dong-Seong Kim*

Kumoh National Institute of Technology

Republic of Korea by mounting an information processing device that is capable of processing data received from external sensor to virtual machine operated independently in the server. In addition, to verify the performance of the system, the user operates a multifunctional console in a virtualized network environment. The performance metrics are target processing time, equipment redundancy performance, load balancing, and we will verify the proposed method by comparing with existing naval combat system against the elements.

In Section II, we explain the designed system model and test-bed. Section III provides performance evaluation and experimental results. Section IV concludes our works and points out the future works.

\section{Naval Combat System based on Network Virtualization}

\section{A. Design of Virtualization Environment}

The exhibition processing software is designed based on a commercial virtualization solution to drive a large number of virtualized logical computers on one physical computer.

Target processing and display performance, network communication performance, and remote access performance requirements should be maintained better than existing systems[8].
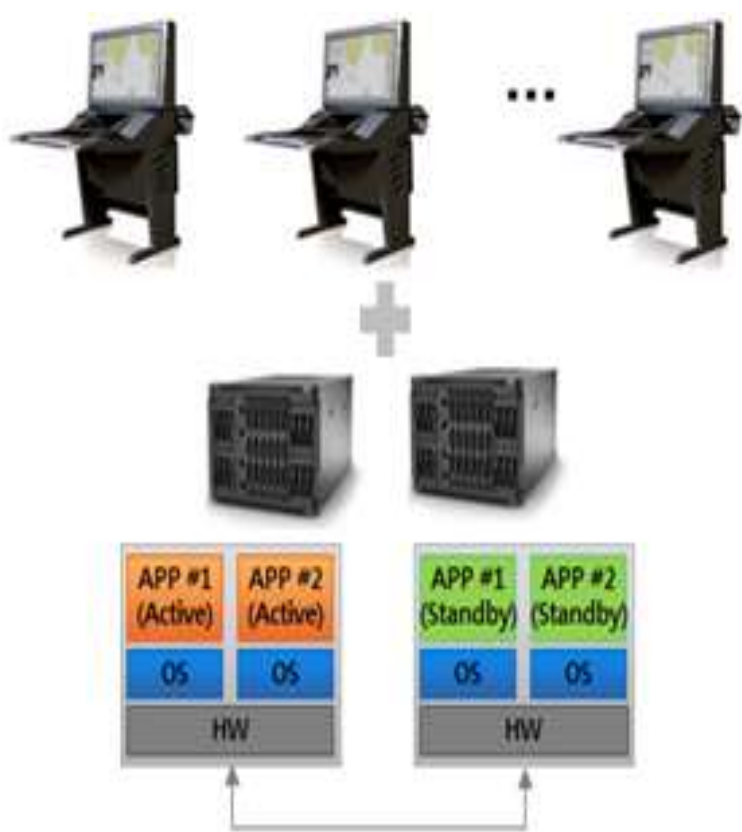

Perform duplication

Figure 1. Design of Naval Combat System Applied Virtualization Technology. 


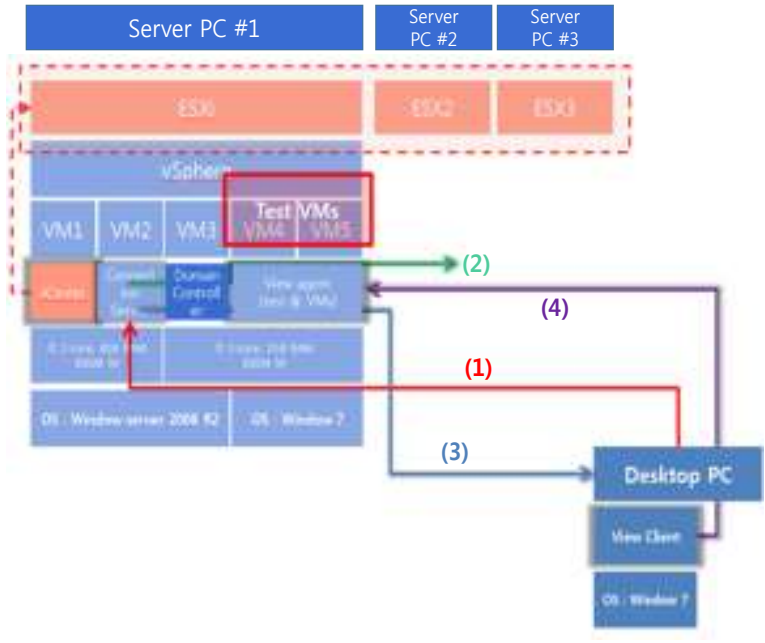

Figure 2. Operation Process between Virtualization Server and Viewclient.

Most of the nodes in naval combat system are in the form of computers[9][10]. Therefore, in order to apply virtualization technology, the CPU, memory, and storage medium must be integrated into the server. When integrated into a single server, the naval combat system can improve maintenance, eliminate noise and heat problems. In addition, if a high-performance computer is applied to the server, it can be expected to improve the network structure by improving the performance and decreasing the number of the network and the cable. Fig. 1 shows the proposed virtualization-based naval combat system, and duplication can be done by hardware exchange of the server.

Fig. 2 shows the overall operation process between virtualization server and view client. First of all, user accesses connection server through view client and enter the ID, password in the window of connection server log. And then connection server informs the IP address information of each VM to desktop PC. Finally it enables the screen of VM to be called from the PC through communication between view client and view agent.

\section{B. Overview of Test-Bed}

Fig. 3 shows the test-bed configuration for analyzing the information processing performance of the existing naval combat system and the system based on the virtualization technology. Test-bed of existing system was constructed based on single board computer (SBC).

Fig. 4 shows a test-bed configuration diagram where a virtualization-based naval combat system is applied to a

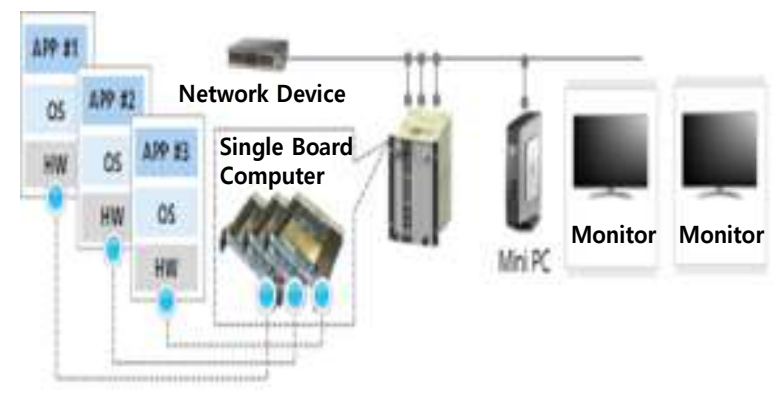

Figure 3. Test-bed of Existing Naval Combat System.

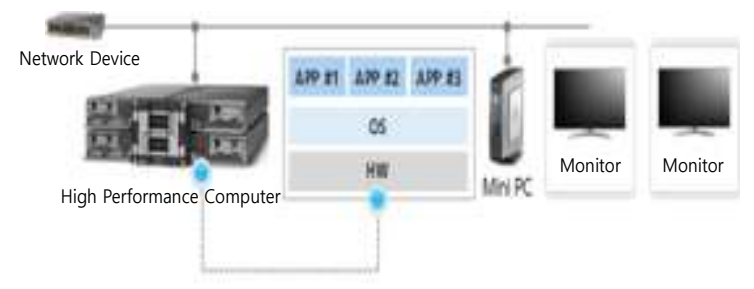

Figure 4. Test-bed of Naval Combat System based on Virtualization.

high-performance computer.

Table I shows the hardware specifications that make up the test-bed of the naval combat system applied the virtualization environment.

\section{Performance Evaluation and Analysis}

Experimental environment of the proposed naval combat system uses DDS communication middleware for data transmission and reception between nodes, and test of transmitting and receiving operation is performed using DDS sample program. Fig. 5 shows the system configuration environment. 2 virtual machines (VMs) and one existing multifunctional console are configured on the same network, and the DDS sample program is run to perform the Pub / Sub operation. It is confirmed that the DDS communication is normally performed in the virtual environment.

Fig. 6 shows how to apply desktop virtualization technology to a multifunctional console before virtualizing and deploying the entire naval combat system.

Finally, complete content and organizational editing before formatting. Please take note of the following items when proofreading spelling and grammar:

The hardware configuration which was composed of the existing separate PC type was changed to the VM type in the high performance computer and the test was performed. Nodes that send and receive naval combat system data other than multifunctional consoles have confirmed the applicability of virtualization technology in the naval

TABLE I. THE HARDWARE CONFIGURATION OF TEST-BED.

\begin{tabular}{|c|c|}
\hline Hardware & Specification \\
\hline $\begin{array}{l}\text { Single Board } \\
\text { Computer }\end{array}$ & - MVMR6100 \\
\hline $\begin{array}{c}\text { High } \\
\text { Performance } \\
\text { Computer }\end{array}$ & $\begin{array}{l}\text { - Intel Haswell 9th Generation } 2.3 \mathrm{GHz} 12 \text {-core, } 2 \\
\text { processors or higher (24+ core) } \\
\text { - DDR4 RAM 96GB or more (ECC Reg RDIMM, } \\
\text { 2133MHz) } \\
\text { - HDD 1.2 TB 10krpm } \\
\text { - NIC 10Gbps or higher (including } 2 \text { or more 10G SFP } \\
\text { transceivers) } \\
\text { - Nvidia GRID K2 graphics } \\
\text { - Apply power and network redundancy } \\
\text { - 19-inch commercial standard rack mount type }\end{array}$ \\
\hline $\begin{array}{l}\text { Network } \\
\text { Device }\end{array}$ & $\begin{array}{l}\text { - Switches over } 1 \text { Gbps } \\
\text { - 19-inch commercial standard rack mount type }\end{array}$ \\
\hline Monitor & - Supports 1920 X 1080 resolution \\
\hline Mini PC & $\begin{array}{l}\text { - DVI output support } \\
\text { - HD screen support } \\
\text { - USB ( } 2.0 \text { or higher) port support } \\
\text { - 1Gbps Ethernet support } \\
\text { - Keyboard, mouse input support }\end{array}$ \\
\hline
\end{tabular}




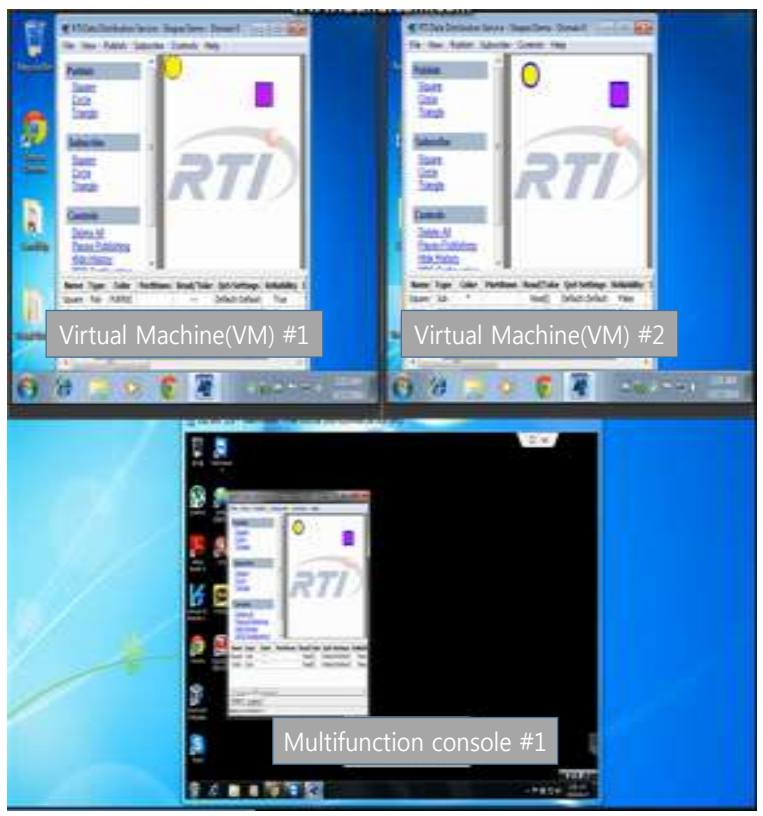

Figure 5. Test Environment of DDS Communication based on Virtualization.

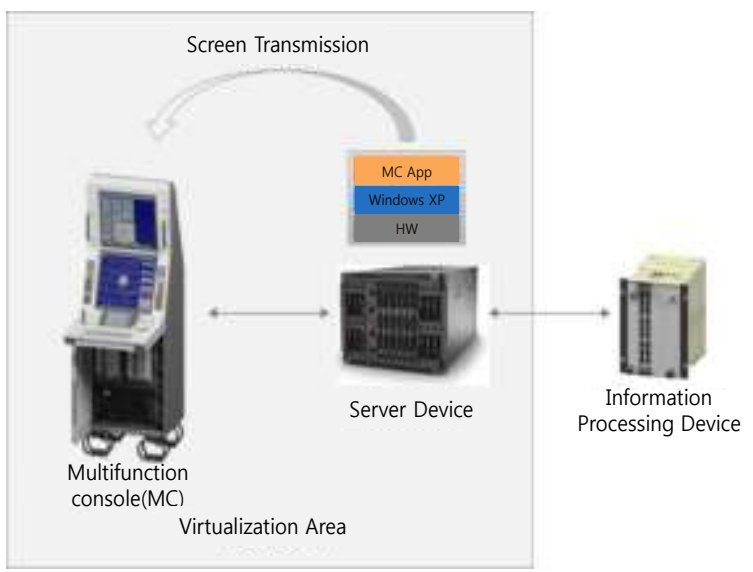

Figure 6. Test Environment of Virtualization Technology.

combat system by using existing naval combat system equipment as it is.

Prior to the simulation test, the naval combat system application software running on the multifunction console was installed on the VM and tested. For the user, the tests were performed to confirm the reactivity and normal functioning, and update the target for the generated target.

\section{A. Processing Power of VM}

Fig. 7 shows the result of measuring the time to process a given number of floating-point operations. Compared with the SBC method, the HPC technique can reduce the computation time by $50 \%$ at $100,000,000$ times and up to $200 \%$ at $500,000,000$ iterations.

\section{B. Memory Operation of VM}

Fig. 8 shows the measurement results of memory data input / output for a given size. Simulation results also show that the HPC method shows improved results compared with the SBC method.

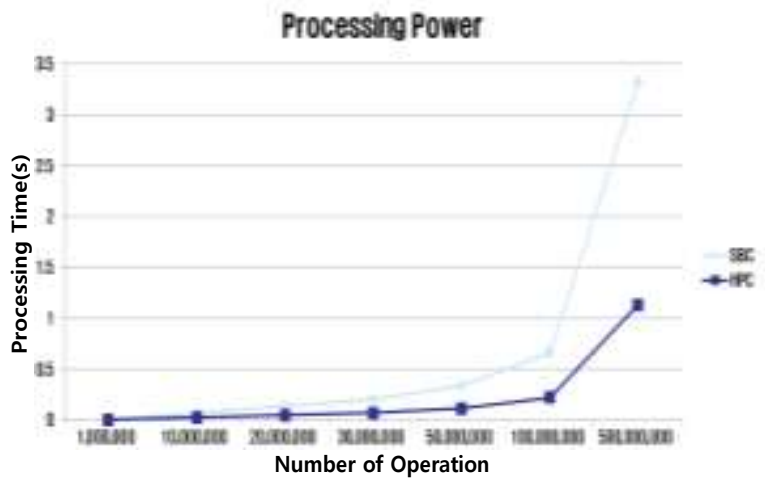

Figure 7. Power Consumption of Service Processing in SBC and HPC.
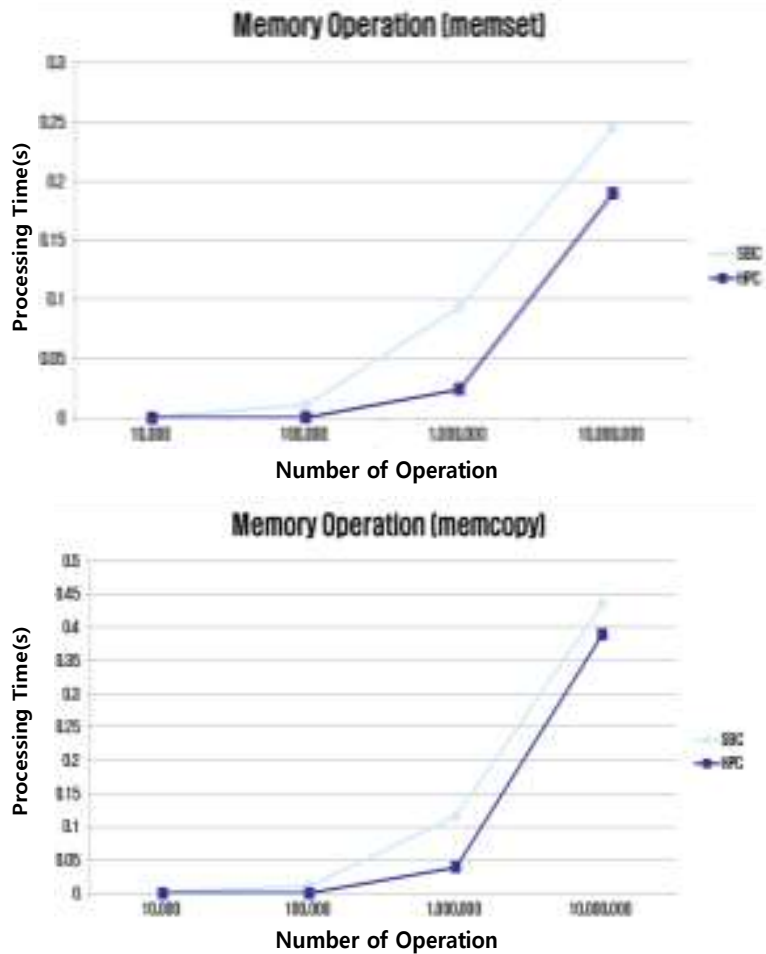

Figure 8. Memory Operating Services of SBC and HPC Comparison Analvsis and Result.

Simulation results show that the system provides the same functions in terms of responsiveness and basic function as compared with the multifunctional console that operated on the existing separate hardware device. Also, it was confirmed that the target update time for the generated target shows the same performance when compared with the existing environment. Based on these points, it can be considered that virtualization technology can be applied to the naval combat system.

\section{Iv. Conclusion and Future Works}

In this paper, we propose a method to improve system compatibility and performance based on virtualization environment using network virtualization technology to naval combat system. The proposed system is implemented by integrating independent VM and interworking with the multifunctional console in the existing naval combat system. In additional, a number of information processing devices 
are mounted on the VM for performance evaluation. As a result, the proposed system shows that delay time and utilization is improved through comparison with the existing naval combat system. Future works will focus on the field of multi-distributed redundancy based on real-time.

\section{Acknowledgment}

This research was financially supported by National Research Foundation of Korea (NRF) through the Human Resource Training Project for Regional Innovation 2015 (NO. NRF-2015H1C1A1035971), the MSIP(Ministry of Science, ICT and Future Planning), Korea, under the "Creative ICT Convergence Human Resource Development Program" (NO. IITP-2017-H8601-15-1011) support program supervised by the IITP(Institute for Information and communications Technology Promotion) and BK21+ Project in Kumoh National Institute of Technology.

\section{References}

[1] D.-S. Kim, S. K. Huh "Distributed Control Networks of Naval Combat Systems," Journal of KIICE, Vol. 13, No. 2, pp. 41-47, Dec. 2012.

[2] Junho Eum, Sangyoon Oh, "Cloud Computing Model to Naval Shipboard Computing System for its High Availability and Optimization," KIISE, Vol. 20, No. 4, 2014

[3] W. Yang, D.-S. Kim, "Enhanced Network Recovery Scheme on RealTime Switched Ethernet for Naval Combat System", International Journal of Communication Networks and Distributed Systems, Vol.14, No.2, pp. 145-163, 2015

[4] N. M. Mosharaf Kabir Chowdhury, Raouf Boutaba, "Network virtualization: state of the art and research challenges," IEEE Communications Magazine, Vol. 47, No. 7, pp. 20-26, 2009.

[5] Reddy, J.M., Monika, J.M., "Integrate Military with Distributed Cloud Computing and Secure Virtualization," High Performance Computing, Networking, Storage and Analysis (SCC), 2012 SC Companion, pp 12001206, 2012.

[6] Marisol Garcia-valls, Tommaso Cucinotta, Chenyang Lu, "Challenges in Real-Time Virtualization and Predictable Cloud Computing," Jounal of Systems Architecture, Vol. 60, No. 9, pp. 726-740, Oct. 2014

[7] Raj Jain, Subharthi paul, "Network virtualization and software defined networking for cloud computing: a survey," IEEE Communications Magazine, pp 24-31, Nov. 2013.

[8] Kerdsri, J., Wipusitwarkun, K., "Network virtualization for military application: Review and initial development of conceptual design," 2012 14th International Conference, pp61-66, PyeongChang, Feb 2012.

[9] Jin Yong Im, Dong Seong Kim, Kyung Sub Song and Yoon Suk Choi, "Design and Realization of Distributed Real-time Message Management Scheme for Naval Combat System Development Tool," Journal of Institute fo Control, Robotics and Systems, Vol. 22, No. 7, pp. 570-577, July 2016

[10] So-Yeon Kim, Sehwa Choe, Sanggi Ko, Seung-Ki Sul, "A Naval Integrated Power System with a Battery Energy Storage System: Fuel efficiency, reliability, and quality of power," IEEE Electrification Magazine, Vol. 3, No. 2, pp. 22-33 June 2015
About Author (s)

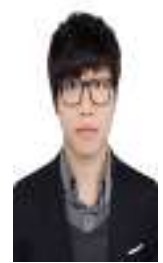

$\mathrm{He}$ is a Master student at IT Convergence Department, School of Electronics Engineering, Kumoh National Institute of Technology, South Korea. His research interests are wireless sensor networks and embedded systems.

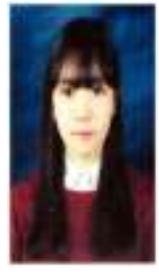

She is a Undergraduate student at School of Electronics Engineering, Kumoh National Institute of Technology, South Korea. Hers research interests are wireless sensor networks and Internet of Things.

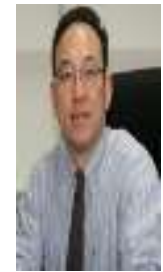

Dong-Seong Kim received his Ph.D. degree in Electrical and Computer Engineering from the Seoul National University, Seoul, Korea, in 2003. From 1994 to 2003, he worked as a full-time researcher in ERC-ACI at Seoul National University, Seoul, Korea. From March 2003 to February 2005, he worked as a postdoctoral researcher at the Wireless Network Laboratory in the School of Electrical and Computer Engineering at Cornell University, NY. He is currently a director of kit Convergence Research Institute and ICT Convergence Research Center supported by Korean government at Kumoh National Institute of Technology. He is IEEE and ACM senior member. His current main research interests are industrial wireless control network, networked embedded system and Fieldbus. 